\title{
Information Professionals 2050: Educational Possibilities and Pathways ${ }^{1}$
}

\author{
"Your task is not to foresee the future, but to enable it." \\ The Little Prince by Antoine de Saint-Exupery
}

This special issue of ISU is a result of a very exciting challenge posed by the School of Information and Library Science (SILS) of the University of North Carolina Chapel Hill. In honor of its 80th anniversary the Dean and faculty invited 16 established information professionals representing four aspects of the information enterprise to discuss their views of the information world of 2050 and how the information profession and professional would need to respond to that world. They further ask what the schools teaching information professionals might do to prepare for that future. The four aspects of the enterprise represented by the invited guests were: Education, Library and Archives, Information Industry and Information Trends or Futures.

The format of the conference was a two-day meeting. Day one was a workshop with the 16 invited participants each giving a short synopsis of their papers. This was followed by extensive discussion among the participants. Day one provided preparation for the second day, which was an open symposium for the community. At the symposium, invited guests in four panels gave more formal presentations, bringing forward our initial thinking and enriching it with what we heard from each other the day before. The perspectives were varied. Going in one wondered how it would all work together toward a perspective of the future. But it was fascinating to see how the different perspectives brought out interrelationships and ideas for creating a roadmap to the future.

At the bottom line, in today's rapidly changing world, thinking 12 months out is difficult enough. But allowing the imagination to think three decades into the future was a luxury of great value. Indeed, there were more questions than answers, but everyone came away with real food for thought.

The conference and the people were exciting. Through this special issue we are delighted to open another pathway to the content of that event to the community. This issue is comprised of an introduction to the overall event by Dean Gary Marchionini and Senior Faculty member Barbara Moran. This is followed by position papers from the invited guest speakers. Barbara Moran provides a concluding paper that highlights thoughts from the panels, which may be found in their entirety in a separate monograph [1].

Throughout the sessions, there was recognition of the importance of interaction among academia and industry, particularly with regard to the need to foster common visions and opportunities for innovation. Shortly after the event, our community was touched by the tragic death of one of those individuals who

\footnotetext{
${ }^{1}$ This work is licensed under the Creative Commons Attribution-Noncommercial No Derivations Works 3.0 Unported license. You are free to Share this work (copy, Distribute and transmit) under the following conditions: attribution, noncommercial and no derivative works. To view a copy of this license, visit http://creativecommons.org/licenses/by-nc-sa/3.0/.
} 
graduated from the SILS and had gone on to help us envision and prepare for our information future. Therefore, it was with sadness but optimism for our future that:

This special issue of ISU is dedicated to the memory of Lee Dirks, '93 graduate of the School of Information and Library Science at the University of North Carolina at Chapel Hill and Director for Portfolio Strategy at Microsoft. Lee and his wife Judy were killed tragically in an automobile accident in August 2012. Lee was an energetic and enthusiastic champion and advocate of scholarly communication, data curation, digital futures and other topics that challenge all information professionals, both today and in the future.

Bonnie C. Carroll

Guest Editor

\section{Reference}

[1] G. Marchionini and B. Moran (eds), Information Professionals 2050: Educational Possibilities and Pathways, School of Information \& Library Science, Chapel Hill, NC, ISBN 978-1-300-20486-2. 